\title{
Reflexões sobre 0 emprego de técnicas e materiais na construção do acervo tátil em museus
}

Elizabeth Romani possui graduação em Arquitetura e Urbanismo pela Universidade de São Paulo (2006), mestrado em Arquitetura e Urbanismo pela Universidade de São Paulo (2011) e doutorado em Arquitetura e Urbanismo pela Universidade de São Paulo (2016). Tem experiência na área de design gráfico, atuando principalmente com design editorial, identidade visual e sinalização ambiental. Atualmente é professora da Universidade Federal do Rio Grande do Norte, onde desenvolve pesquisas nas áreas de design inclusivo e design para crianças.

Juliana Harrison Henno possui graduação em Desenho Industrial pela Fundação Armando Álvares Penteado - FAAP (2004), mestrado em Artes Visuais pela Escola de Comunicações e Artes pela Universidade de São Paulo (2010) e doutorado em Artes Visuais pela Escola de Comunicações e Artes pela Universidade de São Paulo (2016). É designer gráfica e pesquisadora na área de arte, design e mídias digitais. Atualmente coordena e desenvolve pesquisas e atividades práticas sobre a implicação da fabricação digital nas Artes Visuais no PortoFabLab do Espaço Cultural Porto Seguro.<julianahenno@gmail.com>
Resumo Este artigo discute o processo de adaptação de obras artísticas em museus a partir da perspectiva do design inclusivo. Para este estudo, foram selecionados cinco compreendendo duas categorias: aqueles que possuem em seu acervo obras adaptadas para pessoas com deficiência visual e aqueles concebidos para serem museus inclusivos. Neste contexto, partindo-se da assertiva de que a representação da imagem em relevo é um importante canal de informação para o cego, justifica-se um levantamento sobre os atuais métodos adotados na produção de obras inclusivas, de modo a se refletir sobre possíveis alternativas e processos que contribuam para a ampliação desse repertório de imagens. Este artigo pretende ainda refletir sobre possíveis avanços na representação da imagem, migrando-se de uma técnica predominantemente artesanal para uma de cunho digital que possibilitaria uma ampliação do acervo tátil nos museus, entendendo que eles têm grande responsabilidade no processo de inclusão sociocultural do visitante com deficiência visual.

Palavras chave Obra inclusiva, Acessibilidade, Acervo tátil, Museu, Fabricação digital.

\section{Reflections on the use of techniques and materials in the construction of the tactile collection in museums}

Abstract This article discusses the artworks adaptation process in museums from the perspective of inclusive design. For this study, five museums were selected comprising two categories: those that have in their collection artworks adapted for people with visual impairment and those designed to be inclusive museums. In this context, based on the assertion that the representation of the tactile image is an important channel of information for the blind, a survey on the current methods adopted in the production of inclusive works is justified in order to reflect on possible alternatives and processes that contribute to the expansion of this images repertoire. This article also intends to think over possible advances in image representation, migrating from a predominantly handcraft technique to a digital one that would allow an expansion of the tactile collection in museums, understanding that they have a great responsibility in the process of socio-cultural inclusion of the visitor with visual impairment.

Keywords Materials collection, Materials for design, Classification, Cataloguing.

DATJournal v.2 n.12017 


\section{Introdução}

1 O emprego do "universal" traduz

o amplo alcance ao maior número de usuários possível. A expressão “desenho universal" ou "universal design" foi empregada pela primeira vez, em 1985, pelo arquiteto Ron Mace e levou a uma mudança de paradigmas nos projetos de arquitetura e design, estabelecendo que os estes devem atender a qualquer pessoa como pressuposto do termo. Sendo assim, o design universal está relacionado ao papel do projetista em minimizar as desigualdades
O termo "desenho acessível" surgiu na década de 1960 e designa a eliminação de barreiras físicas e arquitetônicas. Nesse período, a premissa era adaptar os ambientes e os produtos já existentes de maneira a torná-los utilizáveis pelas pessoas com deficiência. A discussão do design universal ${ }^{1}$ iniciada por Ron Mace na Universidade da Carolina do Norte abre precedentes para mostrar que o designer exerce também um papel social: o de promover a inclusão das pessoas independentemente de qualquer limitação física.

O desenho acessível é um projeto que leva em conta a acessibilidade voltada especificamente para as pessoas portadoras de deficiência física, mental, auditiva, visual ou múltipla, de tal modo que elas possam utilizar, com autonomia e independência, tanto os ambientes físicos (espaços urbanos e edificações) e transportes, agora adaptados, como os ambientes e transportes construídos com acessibilidade já na fase de sua concepção. (SASSAKI, 1997, p.139)

A partir do entendimento de que todos têm o direito de acesso à cultura, bem como a uma educação integradora, o que já vem ocorrendo no âmbito pedagógico, defende-se neste artigo que o espaço museológico deveria garantir os mesmos direitos de fruição de uma obra de arte ao maior número possível de visitantes. A restrição ao acesso à arte é compreendida como uma barreira comunicacional, que vai contra a promoção da acessibilidade proposta pela Lei no 10.098, de 19 de dezembro de 2000:

\footnotetext{
I - acessibilidade: possibilidade e condição de alcance para utilização, com segurança e autonomia, de espaços, mobiliários, equipamentos urbanos, edificações, transportes, informação e comunicação, inclusive seus sistemas e tecnologias, bem como de outros serviços e instalações abertos ao público, de uso público ou privados de uso coletivo, tanto na zona urbana como na rural, por pessoa com deficiência ou com mobilidade reduzida; (Redação dada pela Lei no 13.146 , de 2015) [...] d) barreiras nas comunicações e na informação: qualquer entrave, obstáculo, atitude ou comportamento que dificulte ou impossibilite a expressão ou o recebimento de mensagens e de informações por intermédio de sistemas de comunicação e de tecnologia da informação;
}

Em junho de 1994, a UNESCO registrou, na Declaração de Salamanca, o termo "sociedade inclusiva". No mesmo ano, Ture Jönsson define sociedade para todos como "uma sociedade que se empenha para acolher as diferenças de todos os seus membros. Isto significa que temos que focalizar nossos esforços não mais em adaptar as pessoas à sociedade e sim em adaptar a sociedade às pessoas" (SASSAKI, 1997, p.166). A evolução deste conceito veio em respos- 
ta à ideia de que a alteração não beneficiaria apenas as pessoas com deficiência, mas a uma ampla quantidade de pessoas que não necessariamente fazem parte do padrão ao qual os projetos se destinam, como por exemplo idosos, obesos, com baixa estatura, ampliando a faixa de atendidos.

O termo "inclusivo" define práticas ou ações que contemplam a inclusão, derivando-se do conceito de acessibilidade. O conceito de design inclusivo pode ser entendido como um desdobramento dos princípios do design universal e que envolve desde o projeto do ambiente até o produto sem barreiras ao usuário. A proposta do design inclusivo parte do pressuposto de projetar para o maior número possível de pessoas e atendendo suas necessidades específicas. $O$ conceito de inclusão pode ser estendido para questões de cultura, gênero e renda. O Design Council (2010) considera os termos "design inclusivo", "desenho universal" e "design for all" como conceitualmente equivalentes.

Este artigo pretende discutir, sob a ótica do design inclusivo, como se dá o processo de adaptação de obras artísticas em museus, analisando os materiais e as técnicas empregadas na produção de peças que ampliam a comunicação tátil do visitante com baixa visão e do cego, bem como sua inserção cultural. Os museus têm uma responsabilidade no processo de inclusão sociocultural que vai além da transposição das barreiras físicas e arquitetônicas, permitindo o acesso à informação e ao acervo. Segundo Tojal (2010), existem dois tipos de acessibilidade em museus: física e sensorial. A acessibilidade física trata de aspectos como barreiras de circulação e equipamentos, além do cuidado na iluminação dos espaços expositivos. A acessibilidade sensorial diz respeito aos aspectos comunicacionais, escrita, visual e audiovisual, defendendo que todas as experiências multissensoriais possam ser aproveitadas por todos os visitantes.

2 Os termos "imagem em relevo" e "obra inclusiva" serão aplicados tanto para designar as obras adaptadas, em que o artista executa a transcrição de uma composição bidimensional para o tridimensional, como para substituição do termo "réplica em relevo", utilizado para definir a reprodução tátil de um original.

\begin{abstract}
A Lei no 11.904, de 14 de janeiro de 2009, que "institui o Estatuto de $\mathrm{Mu}$ seus e dá outras providências", considera como um dos princípios fundamentais dos museus "a universalidade do acesso, o respeito e a valorização à diversidade cultural" (inciso $\mathrm{V}$ do artigo 2o). É à luz desse e dos outros cinco princípios constantes no artigo citado que o Estatuto de Museus deve ser compreendido e aplicado. [...]Art. 35. Os museus caracterizar-se-ão pela acessibilidade universal dos diferentes públicos, na forma da legislação vigente; [...]Art. 42. Os museus facilitarão o acesso à imagem e à reprodução de seus bens culturais e documentos conforme os procedimentos estabelecidos na legislação vigente e nos regimentos internos de cada museu. (COHEN; DUARTE; BRASILEIRO, 2012).
\end{abstract}

Ainda no âmbito do design inclusivo, optou-se por estudar a imagem em relevo ${ }^{2}$ e a reprodução de bens culturais presentes nos museus, acreditando na percepção sensorial como um possível caminho de acesso à arte. 
3 A Galeria Tátil da Pinacoteca é uma proposta de acessibilidade em que as esculturas originais podem ser tocadas somente pelos cegos, sendo esta uma solução na contramão da inclusão, pois apenas uma parcela da população é beneficiada. Nesta proposta, a fruição artística não é atingida apenas pela comunicação tátil; o percurso selecionado é acompanhado por um áudio com a descrição de cada uma das esculturas.

\section{acervo tátil em museus}

Devido a sua finalidade comunicacional, a imagem em relevo apresenta-se de diferentes formas no ambiente museográfico, de modo a atingir eficazmente todos os visitantes. As imagens abordadas neste artigo correspondem às obras geradas a partir de quadros bidimensionais e maquetes físicas de edificações arquitetônicas. As esculturas não foram aqui consideradas como projeto de design, uma vez que são fruto de um trabalho com finalidade artística; no entanto, em alguns museus identificou-se a existência de programas educativos que incluem a apreciação de obras originais por cegos ${ }^{3}$. Optou-se por uma abordagem a partir da técnica aplicada para viabilizar a obra inclusiva, não tendo como enfoque do estudo a percepção tátil do usuário, necessitando-se, para isso, um estudo aprofundado junto com uma equipe multidisciplinar, incluindo psicólogos e educadores. Ao debruçar-se sobre a técnica será possível traçar paralelos entre as iniciativas encontradas e os caminhos oferecidos pelas tecnologias digitais.

0 processo de acessibilidade comunicacional nos museus não envolve apenas um produto tátil, mas o desenvolvimento de programas de ação educativa inclusiva, que, segundo Tojal (2010), identificam as especificidades do público com necessidades especiais. No contexto da metodologia do design, a ação educativa é parte fundamental da problematização, uma vez que a pessoa com deficiência não consegue identificar sozinha os problemas para fruição de uma obra. 0 aspecto educativo, além de exercer um importante papel no início dos projetos, na coleta de dados e na identificação dos problemas, atua em igual relação de importância durante as visitas orientadas, como mediador entre a obra e sua interpretação.

Apesar da importância da ação educativa no processo de acessibilidade em museus, o recorte deste artigo será estabelecido pela análise das obras tridimensionais inclusivas, acreditando que nem sempre o visitante terá à disposição uma interlocução, pois em grande parte dos museus a monitoria é realizada somente com agendamento prévio. Para entender a constituição do acervo tátil, utilizou-se a pesquisa de campo em alguns museus como método de coleta de informação com o objetivo de identificar como esta questão era abordada. Os museus nacionais e internacionais selecionados para essa discussão se diferenciam em duas categorias: aqueles que possuem em seu acervo obras adaptadas (Pinacoteca do Estado de São Paulo - São Paulo; Museu Paulista - São Paulo; Museo Castelvecchio - Verona) e aqueles concebidos para serem museus inclusivos (Museo Tiflológico da ONCE - Madri; Museo Tattile Anteros - Bologna). A diferença entre tais proposições está no projeto das obras que compõem o acervo tátil, bem como nos diferentes graus de preocupação com a disposição desse acervo no espaço museológico. Observa-se que são poucas as obras adaptadas para o tátil, predominando a seleção de uma por sala expositiva e quase sempre restritas à apreciação do visitante com deficiência visual. Já os museus acessíveis, concebidos como tal, são projetados para a autonomia do visitante, tanto na sua locomoção pelo espaço quanto em seu acesso a todas as obras. 


\section{Pesquisa de campo nos museus}

Iniciativas de tornar uma obra de arte inclusiva para todos os visitantes com deficiência visual estão cada vez mais presentes em instituições museológicas, sendo mais frequentes quanto maior for o porte do museu e a verba destinada às ações educativas. Dentre as obras adaptadas, a seleção em geral é feita adotando-se ao menos um dos seguintes fatores: custo, dimensão da obra, sua importância no contexto do acervo e viabilidade técnica. Assim, após a seleção, o processo de produção envolve mão-de-obra especializada, que transcreve a obra original a partir do entendimento dos limites físicos e cognitivos do visitante. $\mathrm{O}$ artista também deve intervir, se possível, quando há necessidade de adaptação da escala original para a dimensão do suporte escolhido.

As visitas descritas a seguir foram realizadas entre 2014 e 2015, sendo previamente agendadas, exceto ao Museo di Castelvecchio, em Verona. Durante a pesquisa de campo foram realizados registros fotográficos e anotações, mas apenas uma das visitas foi acompanhada de um visitante cego (ao Museo Tattile Anteros). Por essa razão, a análise descrita está centrada no projeto de design inclusivo e não abordará pesquisa com o usuário.

A visita à Pinacoteca do Estado de São Paulo foi guiada por Margarete de Oliveira, responsável pelo Programa Educativo Público Especial. A instituição tem como objetivo receber um amplo público com deficiência, assim, os materiais desenvolvidos são multissensoriais, atendendo visitante com deficiência intelectual e auditiva. O projeto de tornar o acervo do museu acessível tem mais de dez anos, e ao longo desse tempo foram constantes as visitas de cegos, porém, como o acervo não sofreu muitas alterações, houve uma diminuição desse público no decorrer dos anos. As salas que contêm os materiais multissensoriais são as do acervo permanente, localizadas no último andar do museu. Os materiais ficam armazenados em carrinhos fechados e com rodízios (Figura 1) como uma forma de tornar seu uso móvel entre as salas, mas preservado de outros visitantes. Este museu é um dos casos em que obras selecionadas foram adaptadas segundo uma ordem de importância, definindo-se um quadro por ambiente expositivo. A adaptação das obras é composta por uma maquete física (Figura 2), pranchas de resina em alto relevo e pranchas de composição em E.V.A.. Quando possível, são inseridas essências nas maquetes, de forma a criar uma memória afetiva nos visitantes.

O projeto de acessibilidade no Museu Paulista nasceu a partir da iniciativa de Denise Peixoto, por volta de 2001, trazendo sua experiência como arte-educadora do MAE-USP. Durante a visita, Denise relata que após desenvolver algumas ações pontuais, o museu foi contemplado com uma verba de agência de fomento para executar um projeto piloto, que teve como objetivo levar o acervo tátil para além dos muros do museu. Nesta iniciativa foi usada uma maleta com peças antigas e reproduções ampliadas da São Paulo do começo do século XX (Figura 3). A proposta já se mostrava um caminho para a inclusão por meio da apreciação de objetos reais retra- 
Figura 1 Carrinho que armazena obras multissensoriais.

Fonte Acervo pessoal das pesquisadoras.
Figura 2 Maquete da obra

O violeiro (1899), de Almeida Júnior.

Fonte Acervo pessoal das pesquisadoras.
Figura 3 Maleta com os objetos reais

para a exploração tátil.
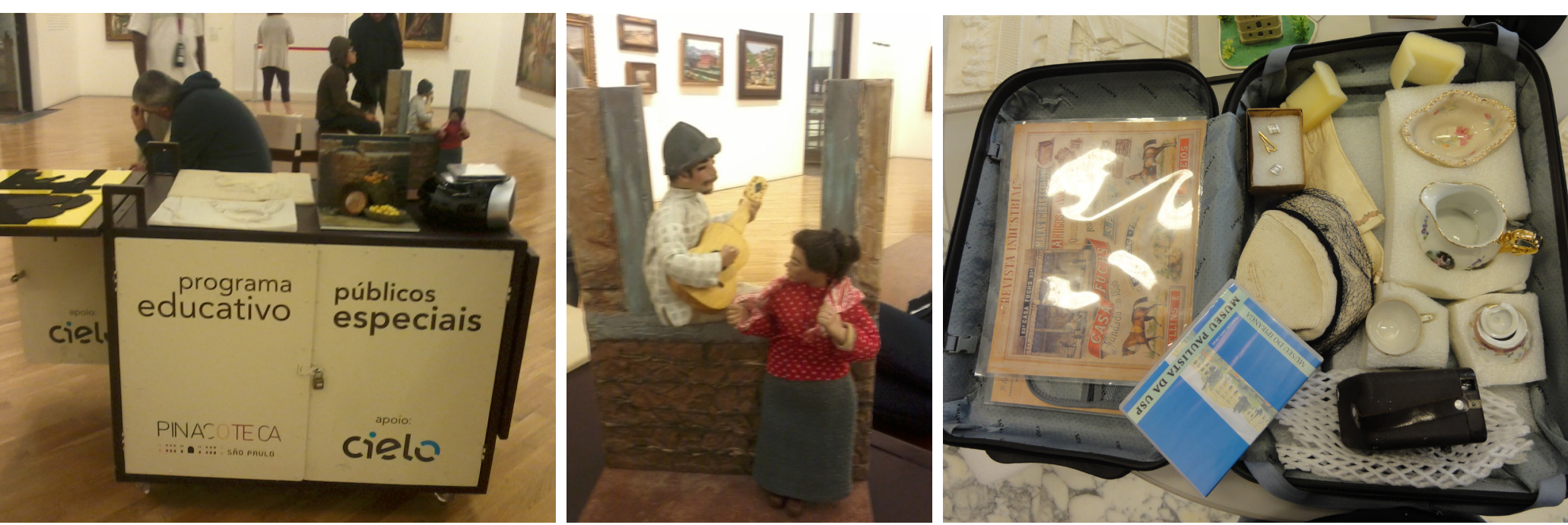

tados nos quadros e assim ressignificados com a mediação. Em meados de 2007, os espaços expositivos que retratam a sociedade paulistana ganharam representações inclusivas do pintor Benedito Calixto. A técnica implantada na adaptação de quadros segue as mesmas diretrizes da Pinacoteca, centrada na produção de peças em resina com relevo (Figura 4). Diferentemente da Pinacoteca, o Museu Paulista deixa o acervo em relevo junto ao quadro, para que todos possam tocar. Além das obras de resina acrílica em relevo construídas a partir de argila esculpida, o programa educativo do museu utiliza objetos soltos que representam fragmentos dos quadros ou do período exposto. A equipe procura aguçar a percepção olfativa com o uso de essências de café e orégano, para fazer uma alusão aos cheiros das ruas comerciais. Todos os elementos associados são utilizados para criar uma atmosfera estimulante e visitante imaginar a época, facilitando a mediação.

Figura 4 Exemplo de obra em relevo produzida a partir de resina acrílica.

Fonte Acervo pessoal das pesquisadoras.

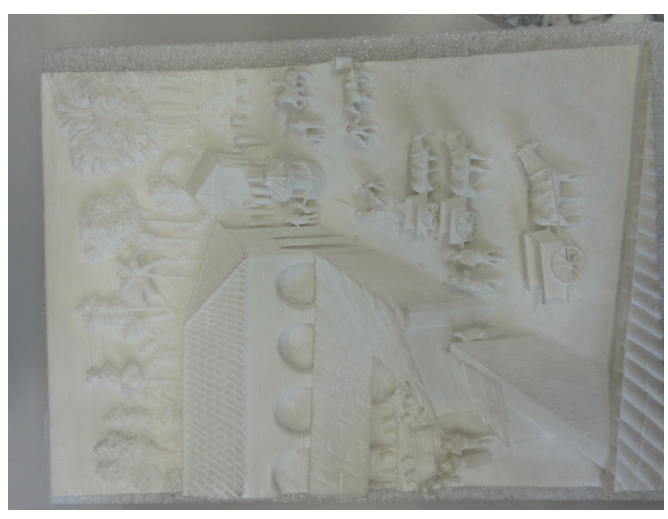

o Museo di Castelvecchio é um dos principais museus da cidade de Verona, por este motivo há a preocupação de tornar acessível ao visitante com deficiência visual algumas pinturas de seu acervo. $O$ castelo medieval que abriga as obras passou por intervenções e adaptações arquitetônicas que melhoraram o acesso dos visitantes. Os espaços foram pensados para que o castelo faça parte da obra, e não seja apenas uma edificação de abrigo de Arte. Apesar do vasto acervo, somente algumas obras são acessíveis aos cegos. Segundo uma funcionária do museu, as obras escolhidas para adaptação aos cegos seguiram dois critérios: importância no acervo e dimensão do quadro. A transposição das obras para uma imagem em relevo obedece à escala aproximada da obra original, em geral mantendo a dimensão próxima de 40 x $60 \mathrm{~cm}$, o que influencia na viabilidade técnica e econômica. As obras são dispostas, sempre que possível, perto da obra original e num canto da 


\section{Considerações sobre as obras inclusivas}

Ao abordar a imagem em relevo, deve-se pontuar que o ensino de desenho para crianças cegas, no Brasil, ainda é um campo em desenvolvimento, e em decorrência desse processo tardio a leitura tátil da imagem não é tão clara como informação se comparada ao texto em braille. A imagem, assim como o braille, é um código de comunicação aprendida na escola, e aqueles que nunca tiveram contato com ele terão maior dificuldade de compreender uma obra inclusiva. Desta forma, não se pode atribuir a responsabilidade da eficiência da proposta de uma imagem em relevo somente à técnica ou ao material empregado em sua confecção; se o visitante não tiver o conhecimento do código, a representação imagética em relevo não servirá como meio de comunicação sem a devida mediação da ação educativa. Todo projeto inclusivo é avaliado por um consultor cego que, além de possuir experiência, possivelmente terá um repertório perceptivo ampliado se comparado aos demais visitantes com deficiência visual. Isso também explica as diferenças de tratamento entre as obras nos museus citados. No entanto, após as visitas, fica claro que a proposta de uma obra inclusiva deverá sempre sofrer adaptações em relação à obra original; princípio semelhante é aplicado no ensino de arte para crianças, como apontado por Cardeal (2011, p. 149):

Percebeu-se que a simples transcrição para o relevo de uma imagem originalmente concebida para a percepção visual, sem adaptá-la à realidade perceptiva tátil, apenas corrobora a imposição de códigos visuais a quem a eles não tem acesso, em nome de uma inclusão que, de fato, acaba se tornando ineficaz.

O método de ensino de desenho para crianças cegas desenvolvido por Duarte (2011) com o objetivo de ampliar a educação artística infantil remete ao processo aplicado nos museus paulistanos para tornar a obra de arte inclusiva. A autora explica que o ensino do desenho segue as seguintes etapas: 1 . reconhecimento do objeto em experiência tátil. Objetos reais quando couberem na mão, ou maquetes tridimensionais para objetos maiores (evitando a fragmentação da percepção). Nesse momento deve-se entender o objeto como um todo; 2. planificação do desenho gráfico numa superfície com espessura (por exemplo, material emborrachado); 3. entender o contorno e assimilar as linhas do desenho com o dedo, sempre obedecendo um mesmo sentido para fixação gráfica.

Além da teoria do ensino de arte para cegos, notou-se que a produção tátil atende a diferentes finalidades, tais como verba e viabilidade técnica; desta maneira, as obras inclusivas refletem a demanda de cada espaço museológico. $\mathrm{O}$ museu concebido para um usuário com deficiência visual apresenta diferenças em relação a um espaço cujo acervo é composto de obras adaptadas para a comunicação tátil. A primeira delas é a disposição 
5 A normatização envolvida nos processos de fabricação digital e a subsequente documentação de projetos permite a reprodução de uma mesma imagem original em diferentes espaços que compartilhem de um mesmo repertório de máquinas e processos. Os laboratórios da rede internacional FabLab (http://fab.cba.mit.edu/about/ faq/) ampliam o acesso à comunidade permitindo que aqueles que não têm recursos para a aquisição dos equipamentos também tenham acesso a este tipo de tecnologia
Reflexões sobre o emprego de técnicas e materiais na construção do acervo tátil em museus

das peças no acervo, permitindo a fruição de todos os visitantes, uma vez que as peças em exposição são mais resistentes ao manuseio. Outra diferença é a uniformidade das propostas técnicas como solução, predominando a maquete tridimensional de representação arquitetônica e representações em relevo da obra de arte original. Em ambos os casos, os produtos são gerados a partir de processos artesanais ligados a técnicas artísticas, tais como modelagem de uma matriz para confecção do produto final, exceto na maquete física de madeira, em que a produção, ainda que artesanal, já é a obra. Tais processos manuais demandam tempo e mão-de-obra qualificada, o que torna cada obra inclusiva onerosa, por isso as réplicas são produzidas sob demanda. Desta forma, o caráter artesanal inviabiliza significativamente a ampliação do acervo de obras táteis no espaço dos museus.

Na tentativa de reverter esta realidade é que se justifica comparar as iniciativas encontradas nos museus com as possibilidades oferecidas pelos meios digitais de fabricação. Se está claro que os processos artesanais de produção, apesar de únicos e de qualidade, não atendem uma incontestável necessidade de inserção cultural do indivíduo com deficiência, faz-se necessário investigar outras possibilidades de produção da obra inclusiva. A fabricação digital contempla um conjunto de processos numericamente controlados pelo computador que permitem a produção física de objetos precisos baseados em um arquivo digital combinando-se, para isso, diferentes técnicas e materiais. Interessa a este artigo o entendimento das técnicas de produção subtrativa e aditiva. O sistema subtrativo faz uso da técnica que, conforme Celani (2008, p.32), "desbasta seletivamente [um bloco de material] por fresas que se movem automaticamente em diversas direções (tipicamente em três eixos)". O sistema aditivo permite a sobreposição de camadas de um material obedecendo um controle numérico até que se forme o objeto em três dimensões. O modelo geométrico digital que forma a imagem é fatiado horizontalmente por um software e cada uma dessas fatias, cuja quantidade varia de acordo com a resolução pré-definida do objeto, será impressa e sobreposta recriando aquele objeto virtual no plano físico por meio de material sólido. Devido à precisão e a possibilidade de se trabalhar com diferentes tipos de materiais, a fabricação digital apresenta-se como uma maneira de viabilizar e ampliar o presença da obra tátil em museus quando comparada aos materiais já disponíveis nas instituições. Por englobar diferentes técnicas, espera-se que quem for manipular o arquivo digital tenha um conhecimento básico das interfaces digitais. Esse trabalho pode tanto ser encomendado como também realizado pelo setor Educativo no caso de o museu ter acesso aos equipamentos ${ }^{5}$. Quando esse tipo de tecnologia é considerada em relação ao cenário da produção tátil atual para museus, amplia-se a viabilidade técnica das obras inclusivas tanto pelo aspecto do custo quanto pelo tempo de produção. 


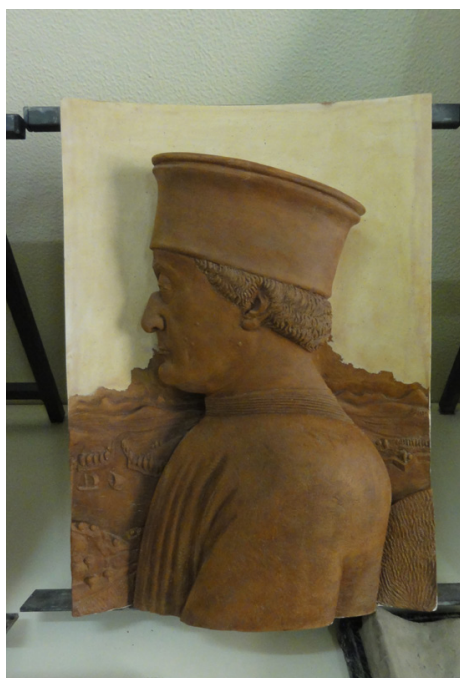

Figura 11 Matriz esculpida em argila do retrato renascentista de Federico Montefeltro.

Fonte Acervo pessoal das pesquisadoras.

As réplicas de obras em pranchas de alto relevo estão presentes em quase todos os museus visitados, sendo que a diferença está no uso do material da obra final. O processo inicia-se com a produção de uma matriz, de argila (Figura 11) ou de plastilina, esculpida manualmente pelo artista, posteriormente gerando-se um molde de silicone em negativo (Figura 12) que possibilita a produção do alto relevo de gesso ou de resina acrílica e, por fim, o processo de polimento para o acabamento da peça. Cada material apresenta aspectos positivos e negativos: o gesso, por exemplo, necessita de constante limpeza e manutenção, mas por outro lado apresenta uma característica de conforto ao toque, podendo ser manuseado por horas sem gerar estresse nos dedos. A resina acrílica apresenta maior durabilidade, dispensando manutenção, entretanto sua superfície não é tão confortável ao toque, pois dependendo do relevo é gerado um atrito durante a leitura, causando dormência nas pontas dos dedos.

Em contraponto a este cenário, a fabricação digital permite uma simplificação do processo de produção da matriz de relevo, uma vez que é possível pelo sistema subtrativo desbastar um bloco de material conforme as orientações do arquivo digital de um relevo tridimensional. Para que isso seja possível, é necessária a captura digital de um volume original (pelo processo de digitalização 3D) ou a modelagem em software tridimensional. Uma fresadora CNC, por exemplo, desbasta, por meio de fresa, materiais como o MDF (Figura 13), o compensado de madeira, a espuma de poliuretano, entre outros. A possibilidade de se utilizar esta técnica para realizar matrizes ou modelos finais permitiria que museus ampliassem seus acervos de obras táteis, bastando para isso converter corretamente as imagens originais para o plano digital de modo a serem desbastadas no material final. A versatilidade desse método está na possibilidade de escolher diferentes materiais, caso se opte pela produção de matriz ou contra-fôrma.

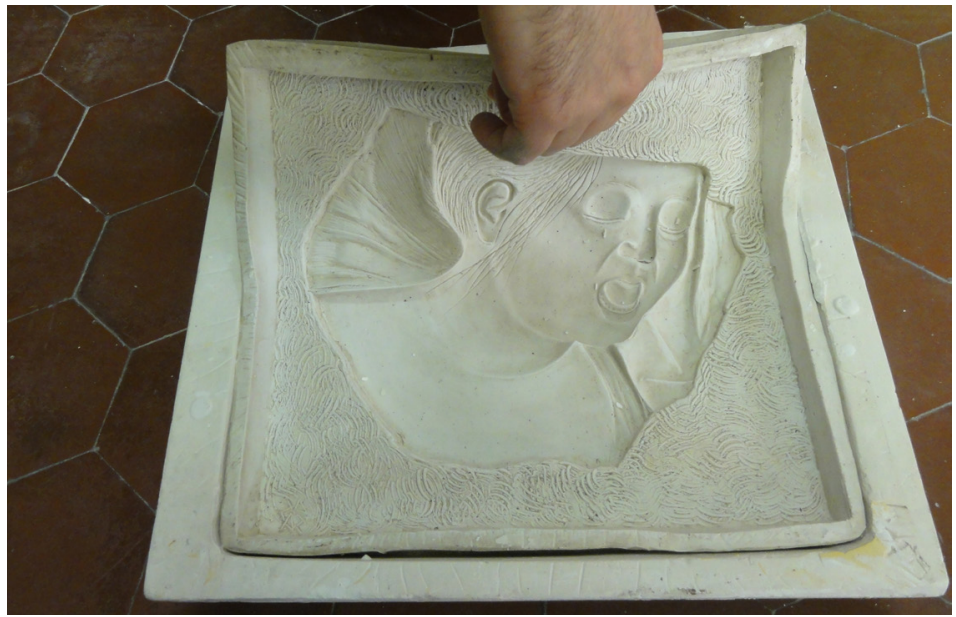

Figura 12 Molde de silicone produzido no Museo Tattile Anteros. Fonte Acervo pessoal das pesquisadoras.

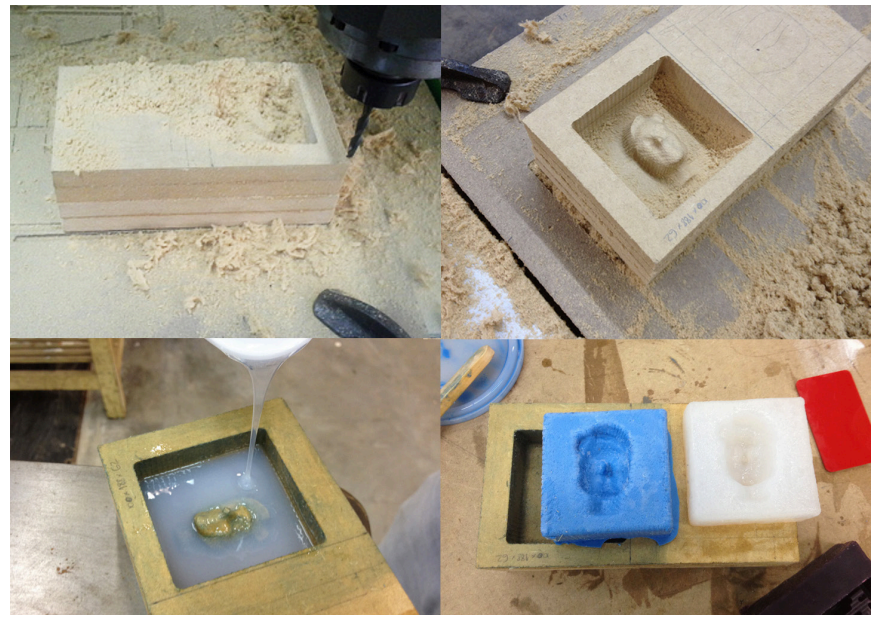

Figura 13 Etapas na produção de um molde em MDF utilizando uma fresadora CNC.

Fonte Acervo pessoal das pesquisadoras. 

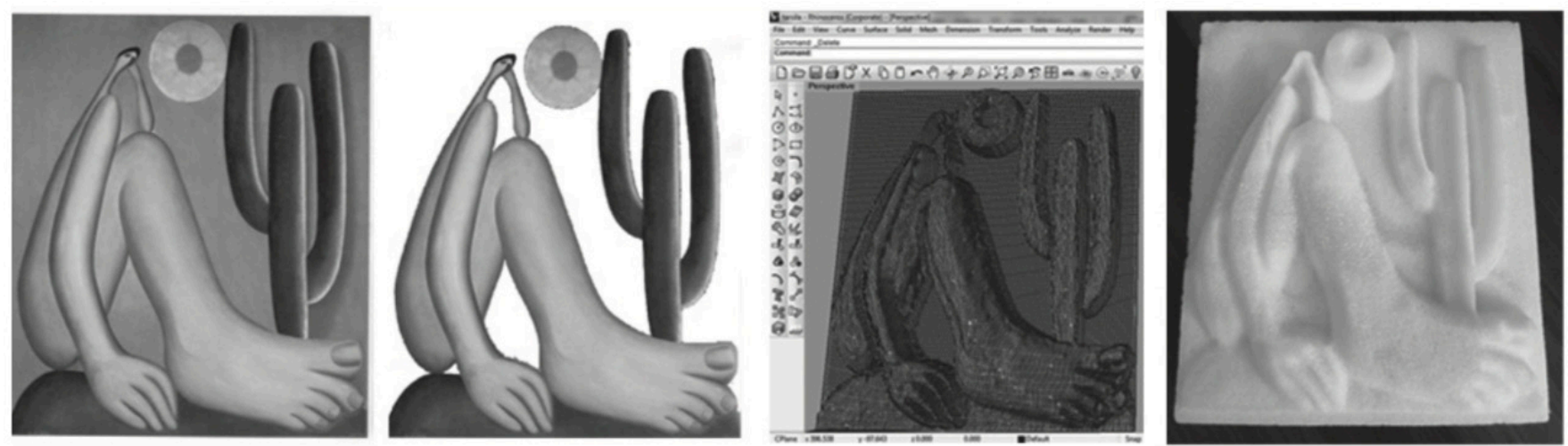

Figura 14 Digitalização da imagem original até sua produção usando uma fresadora CNC. Fonte Cardoso et al. (2011).

Em nenhum dos museus de arte analisados foram conduzidos experimentos no sentido de transcrever o acervo original para o relevo por meio dos processos digitais, porém existem alguns experimentos isolados, como aquele dos pesquisadores Cardoso et al. (2011), da Universidade Federal do Rio Grande do Sul, que propuseram uma maneira de converter os dados de uma imagem bidimensional para um software 3D que simula um relevo tridimensional baseado no contraste da figura (Figura 14).

Já a iniciativa de se utilizar o método aditivo de produção para comunicar uma transcrição visual para o cego foi descrita por Celani \& Milan (2007). Nesse projeto (Figura 15), dois tipos diferentes de mapas táteis para o edifício da Biblioteca Central da UNICAMP foram realizados utilizando-se a técnica da sinterização seletiva a laser e os resultados demonstraram que o modelo foi facilmente compreendido pelo visitante cego, facilitando o reconhecimento do espaço do edifício em questão. 0 experimento parte do desenho simplificado da planta do edifício, da inserção de instruções em braille e da variação de altura de paredes e obstáculos. A técnica escolhida garantiu maior resolução e durabilidade ao modelo final, que foi posteriormente apresentado a um público de pessoas cegas. Tal técnica demonstra que uma vez definido o modelo, ou tendo-se em vista a imagem a ser transcrita para o plano físico, é possível reproduzi-la, rapidamente, com extrema precisão. No entanto, é importante salientar que a variedade de materiais e texturas possíveis bem como seu custo dependem do equipamento utilizado.

Figura 15 Modelos impressos de mapas táteis por meio de estereolitografia. Fonte Celani \& Milan (2007).

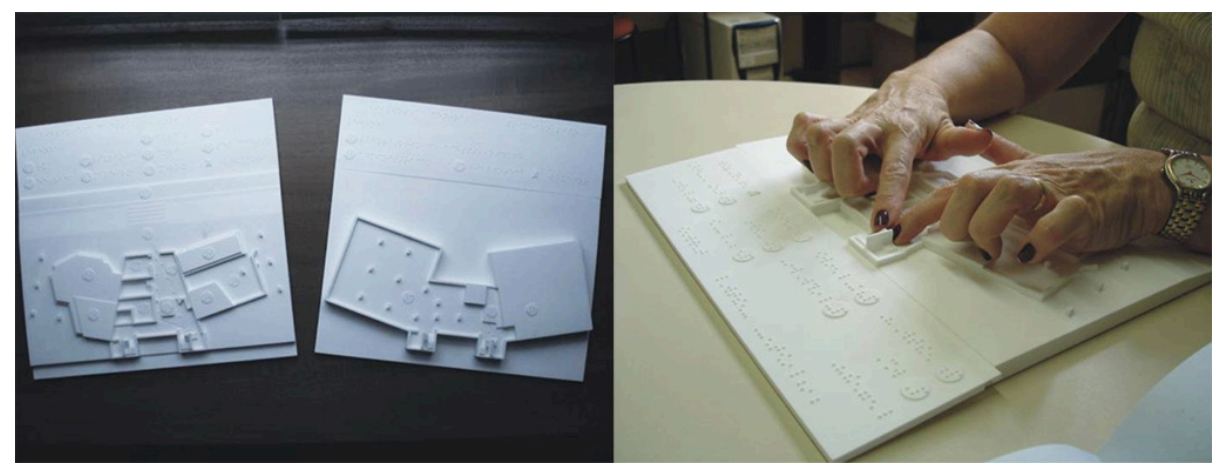

DATJournal v.2 $\mathrm{n} .12017$ 


\section{Considerações finais}

Nos museus, a leitura da imagem em relevo pelos cegos é restrita a poucos materiais de caráter educativo. Acredita-se que é papel desses espaços ampliarem seu repertório imagético, promovendo o diálogo entre fruição e representação artística. A pesquisa de campo mostrou que ainda hoje os museus necessitam aumentar seu acervo inclusivo, sendo que nos casos estudados a obra tátil é um objeto confinado a que os visitantes não têm livre acesso, seja pela pequena quantidade ou pela fragilidade do material. Dessa forma, uma obra que deveria permitir a leitura tátil para todos os visitantes, apresenta-se como uma peça restrita aos cegos.

$\mathrm{O}$ artigo apresenta a fabricação digital como alternativa para reverter a escassez de obras inclusivas no espaço expositivo dos museus, uma vez que partindo de um modelo geométrico digital da obra original é possível materializá-la tanto no plano bidimensional, no caso do recorte, quanto no plano tridimensional, nas possibilidades de produção de matriz de relevo ou diretamente como uma imagem em relevo final. Ao analisar as técnicas empregadas nos museus, avaliou-se que em grande parte dos casos ainda impera um método artesanal de produção, o que resulta na pequena quantidade de obras inclusivas no acervo, desestimulando a frequência da visita de pessoas com deficiência visual. Para além do acervo tátil permanente do museu, a fabricação digital viabiliza que exposições temporárias também sejam acessíveis, o que não ocorreu em nenhum dos espaços visitados.

A possibilidade de se adaptar diferentes técnicas e materiais que necessitem de menor manutenção representa um avanço quando comparada ao atual cenário da produção da imagem em relevo, ampliando o seu alcance ao disponibilizar um acervo cada vez maior. A técnica digital também pode ser pensada de maneira a ampliar as diferenças perceptivas em cada uma das obras, explorando materiais, texturas e temperaturas. Tal iniciativa se mostra relevante uma vez que torna viável a reprodução de uma mesma peça quantas vezes forem necessárias, caso se deseje disponibilizar uma mesma obra em mais de um museu no âmbito nacional e ou até internacional. 


\section{Referências bibliográficas}

CARDOS, E.; TEIXEIRA F.G.; SILVA, R.P.; SILVA, T.L.K. Fabricação digital de recursos táteis aplicados do design de exposição. Augmented Culture: Proceedings of the 15th Iberoamerican Congress of Digital Graphics, 2011, 330-334. SIGraDi. Santa Fe, Argentina.

DUARTE, M. L. B. Desenho infantil e seu ensino a crianças cegas: Razões e Método. Curitiba: Editora Insignt, 2011.

CARDEAL, M. Metáforas visuais - redundâncias táteis. In: DUARTE, M. L. B., PIEKAS, M. I. (org.). Desenho infantil em pesquisa: imagens visuais e táteis. Curitiba: Editora Insignt, 2011. CELANI, M.G.C., MILAN, L.F. 2007. Tactile scale models: three-dimensional info-graphics for space orientation of the blind and visually impaired. 3rd International Conference on Advanced Research in Virtual and Rapid Prototyping, VRAP 2007, Leiria, Portugal, pp. 1-10. CELANI, G., PUPO, R. Prototipagem Rápida e fabricação digital para arquitetura e construção: definições e estado da arte no Brasil. In: Cadernos de Pós-Graduação em Arquitetura e Urbanismo, Universidade Presbiteriana Mackenzie. São Paulo, 2008, Vol.8, No.1, p.31-41.

COHEN, R.; DUARTE, C. e BRASILEIRO, A. Acessibilidade a Museus. Brasília, DF: MinC/Ibram, 2012. LEMOS, E.R. [et al.]. Normas Técnicas para a produção de textos em braille. Brasília: Ministério da Educação, Secretaria de Educação Especial, 2006.

TOJAL, A. F. Acessibilidade e inclusão de públicos especiais em museus. In: Caderno de acessibilidade: Reflexões e Experiências em Museus e Exposições. São Paulo: Expomus, 2010. 